\title{
Just the facts: Pediatric Dental and Oral Injuries
}

\author{
Aaron K. Sibley $\odot, \mathrm{MD}^{*}$; Paul Atkinson, MB, MA ${ }^{\dagger}$; Kevin Lobay, BSc, DMD, MD, MBA ${ }^{\ddagger}$ \\ CLINICAL SCENARIO
}

A 16-month-old presents to the emergency department (ED) after a fall while running at home. Her mother noted some blood in the child's mouth and believed there was a tear in the skin above the front teeth.

\section{Do labial frenulum tears require acute management?}

As there is a lack of evidence available to help answer this question, we rely on expert opinion. Suturing is generally not required, and most will need only a temporary soft diet. If the laceration extends into the vestibular fold (border of gingival and oral mucosa), then repair is likely necessary and may require an oral surgeon depending on the severity. ${ }^{1}$

\section{What about tongue lacerations? Do they need to be sutured?}

Again, recommendations regarding repair of pediatric tongue lacerations are mostly consensus based. In general, length appears to be the most significant factor for clinicians in determining if a wound can be managed conservatively. ${ }^{2}$ Most lacerations managed by secondary healing do extremely well with a median 6.2 days of complaints, compared with 13 days for more complicated wounds treated with sutures. ${ }^{2}$ Scarring is present in about one-third of patients managed conservatively and in just more than one-half of cases managed by sutures, and rates of complications including infection are very low regardless of management strategy. ${ }^{2}$ We recommend clinicians use the Zurich Tongue Scheme (Figure 1$)^{2}$ to guide management decisions. Gaping injuries to the tip of the tongue, as well as injuries to the dorsum of the tongue that are gaping and more than $2 \mathrm{~cm}$ in length, should be closed primarily. It is important to examine the tongue in the resting position while assessing for gaping. Further, wounds with active hemorrhage or wounds that bisect the tongue may require repair. ${ }^{2}$ If a laceration has been determined to require intervention, deep absorbable sutures closing all layers in a single stitch should be used. Local analgesia might include gauze soaked in $4 \%$ lidocaine placed over the wound, local injection of lidocaine with epinephrine, or a lingual nerve block. ${ }^{1}$ Many children will require sedation increasing the both time and risks of repair.

\section{Is there a particular pattern of oral injuries that might raise suspicion for non-accidental injury?}

A recent systematic review of pediatric oral and dental injuries related to abuse did not find evidence of a pathognomonic pattern, although oral injuries should prompt further evaluation for additional injuries. ${ }^{3}$ Injuries to the lips may be the most common oral injury in abuse, ${ }^{5}$ and bruising to the face and neck, in particular the left ear (from a right handed strike), may increase the likelihood of the injury being non-accidental. ${ }^{3}$ Labial frenulum tears have traditionally been identified as a potential sign of non-accidental injury from forcing of a bottle or pacifier; however, an isolated tear

From *University of Prince Edward Island, Faculty of Science, Paramedicine, Charlottetown, PE; †Dalhousie University, Department of Emergency Medicine; and the $¥$ University of Alberta, Faculty of Medicine and Dentistry, Department of Emergency Medicine and School of Dentistry.

Correspondence to: Dr. Aaron Sibley, University of Prince Edward Island, 550 University Ave, Rm 430 Duffy Science Centre, Charlottetown PE, C1A 4P3; Email: asibley@upei.ca

(C) Canadian Association of Emergency Physicians

CJEM 2020;22(1):23-26

DOI 10.1017/cem.2019.440 


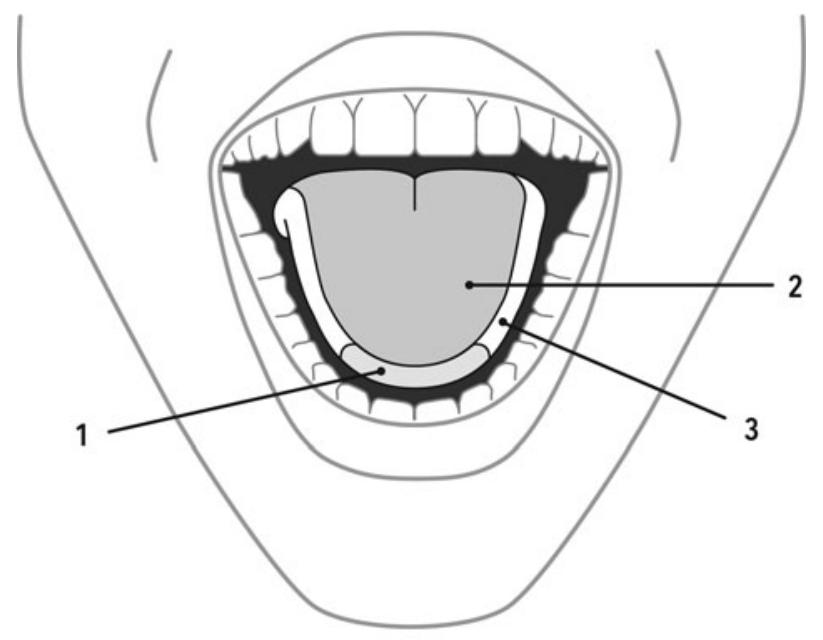

1. Gaping wound edges: TL suturing mandatory

2. $\geq 2 \mathrm{~cm}$ and gaping wound edges: TL suturing recommended

3. TL suturing optional

*Tongue examined at rest

Figure 1. Zurich Tongue Scheme. From: Seiler M, Letizia MS, Georg S, Clemens S. Tongue lacerations in children: to suture or not. Swiss Med Wkly 2018;148:w14683. Modified with permission from EMH Swiss Medical Publishers Ltd.

does not seem to be more common in abused children. ${ }^{4}$ It is important to know pediatric milestones (e.g., when children can roll or walk) to help judge the likelihood of the described injury mechanism.

\section{A single tooth is pushed out of place. Should you correct this acutely?}

When blunt injury to a primary tooth occurs, a dentist should evaluate the injury within one week. Guidelines for pediatric dental trauma have been published by the International Association of Dental Traumatology (IADT) and endorsed by the American Academy of Pediatric Dentistry. ${ }^{5}$ These guidelines are available in pdf format both online and through the IADT's free "ToothSOS" app. In general, injured primary teeth that are tender to percussion but remain in proper position (concussed) or that are slightly mobile (subluxed) do not require any specific treatment other than pain control and a soft diet. Primary teeth that have been minimally displaced but remain firmly in place may be left to drift back into position spontaneously if they do not interfere with occlusion. Primary teeth that have been significantly impacted (intrusive luxation) can often be left to spontaneously re-erupt. Primary teeth that are significantly displaced $(\geq 3 \mathrm{~mm})$ and very mobile can be gently removed after local infiltration of anesthesia by grasping them with a dry $2 \times 2$ gauze. Avulsed permanent teeth should be replanted within one hour, but avulsed primary teeth are never replanted.

\section{What are the most useful anesthetic blocks for dental injuries? How can I provide anesthesia to max- illary and mandibular teeth?}

Emergency physicians should be familiar with two easy-to-perform dental blocks: the inferior alveolar nerve block for mandibular teeth, and supraperiosteal infiltration for maxillary teeth. The inferior alveolar nerve block involves infiltration of approximately $2 \mathrm{cc}$ of local anesthetic on the lingual aspect of the posterior mandible, where the inferior alveolar nerve enters the mandibular canal (the nearby lingual nerve may also be anesthetized concurrently). Maxillary teeth can be anesthetized using supraperiosteal infiltration of 1-2 cc of local anesthetic into the alveolar mucosa just 


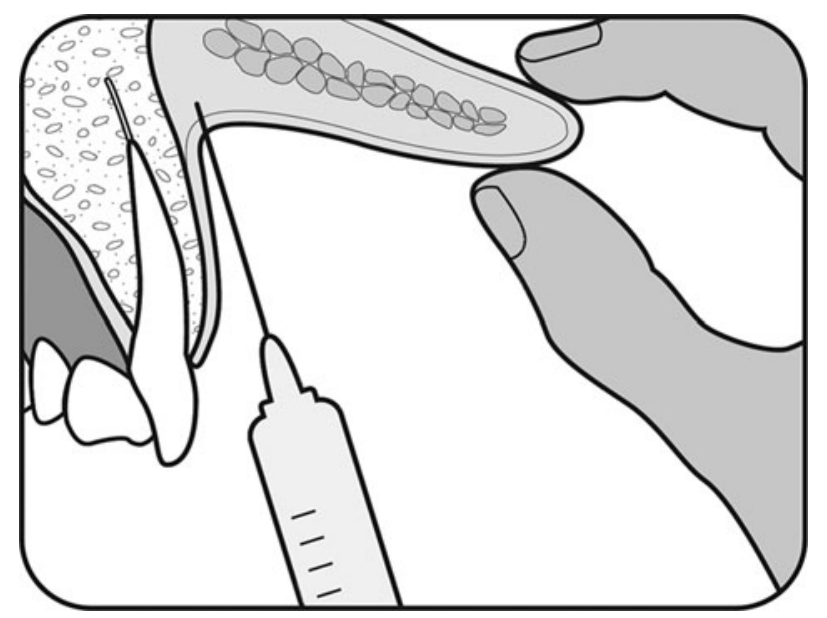

Figure 2. Supraperiosteal infiltration (cross-section of the lip and maxilla): After drying the area, apply $18 \%$ benzocaine gel to the muccobuccal fold. Wait 1-2 minutes, then advance a 25-27 gauge needle 3-4 mm into the height of the muccobuccal fold, in line with the tooth. Inject 1-2 cc of local anesthetic, then wait several minutes to allow penetration of the bone.

labial (or buccal) to the affected maxillary tooth (Figure 2). Prior topical application of $18 \%$ benzocaine gel may mitigate pain from needle insertion.

\section{SUMMARY}

Most pediatric oral and dental injuries require only conservative therapy. The Zurich Tongue Scheme can help guide clinicians when making decisions regarding primary closure of tongue lacerations. A dentist should evaluate patients with blunt trauma to the primary teeth within the week, perhaps earlier if there are concerns regarding impacted teeth, mobile teeth, or occlusal interference. If necessary, the inferior alveolar nerve block or supraperiosteal infiltration can provide temporary pain relief.

\section{KEY POINTS}

- Labial frenulum tears can be managed with soft diet alone.

- Most tongue lacerations do not require sutures.

- No one oral or dental injury including a labial frenulum tear is pathognomonic for abuse, and clinicians should examine the patient for other signs of abuse.

- Avulsed primary teeth should never be replanted.

- Infiltration of local anesthetic can provide effective temporary pain relief.

Keywords: Dentistry and oral medicine, emergency medicine, trauma

Competing interests: None. 
Aaron K. Sibley et al.

\section{REFERENCES}

1. Brown DJ, Jaffe JE, Henson JK. Advanced laceration management. Emerg Med Clin N Am 2007;52:83-99.

2. Seiler M, Massaro SL, Staubli G, Schliestl C. Tongue lacerations in children: to suture or not. Swiss Med Wkly 2018;148:w14683.

3. Sarkar R, Ozanne-Smith J, Bassed R. Systematic review of the patterns of orofacial injuries in physically abused children and adolescents. Trauma Violence Abuse 2019;1-11.

4. Maguire S, Hunter B, Hunter L, et al. Diagnosing abuse: a systematic review of torn frenulum and other intra-oral injuries. Arch Dis Child 2007;92:1113-7.

5. Malmgren B, Andreasen JO, Flores MT, et al. Guidelines for the management of traumatic dental injuries: 3 . Injuries in the primary dentition. Dent Traumatol 2012;28:174-82. 